\title{
УРОВЕНЬ ВИТАМИНА D У ДЕВОЧЕК ПОДРОСТКОВОГО ВОЗРАСТА С ЗАБОЛЕВАНИЯМИ МОЛОЧНЫХ ЖЕЛЕЗ
}

\author{
Гуменюк О.И., Черненков Ю.В.
}

ФГБОУ ВО «Саратовский государственный медицинский университет им. В.И. Разумовского», г. Саратов

Молочные железы - гормонозависимый орган, физиологическое состояние и патология которых напрямую зависит от функционирования эндокринных желез. В последние десятилетия обсуждается роль дефицита витамина D в развитии заболеваний молочных желез. Активная форма витамина D обладает антипролиферативной и проапоптотической активностью в ткани молочных желез [1-3].

Изучение влияния дефицита витамина D на развитие заболеваний молочных желез у девочек подросткового возраста - актуальная проблема современной педиатрической эндокринологии и гинекологии.

ЦЕЛЬ: определить уровень витамина D у девочек подросткового возраста с заболеваниями молочных желез.

ПАЦИЕНТЫ И МЕТОДЫ: определен Уровень витамина D 25(ОН)D в сыворотке крови методом хемилюминесцентного иммуноанализа на микрочастицах у 27 девушек с заболеваниями молочных желез в возрасте 14-17 лет (группа I), не принимавших препараты витамина D и 11 девушек аналогичного возраста без патологии молочных желез, не принимавших препараты витамина D (контрольная группа). Согласно, Российским рекомендациям оптимальной концентрацией $25(\mathrm{OH}) \mathrm{D}$ в сыворотке крови считали уровень 30-100 нг/мл, недостаточной — от 20 до 30 нг/мл и дефицитом - менее 20 нг/мл [4,5]. Статистический анализ полученных результатов проводился при помощи программы SPSS Statistics v 24.0.0.0. Статистическая значимость определялась при уровне $\mathrm{p}<0,05$.

РЕЗУЛЬТАТЫ: в группе І все пациентки (100\%) предъявляли жалобы на циклические масталгии; в 83\% случаях диагностирована кистозная дисплазия молочных желез, 9\% - железистая дисплазия, в остальных случаях (8\%) - фиброзная дисплазия. Диагноз верифицировался на основании жалоб, клинического осмотра и ультразвукового исследования. При исследовании уровня 25(OH)D в сыворотке крови в группе I его концентрация была ниже 20 нг/мл у всех пациенток (Ме 13,4 нг/мл), что характерно для дефицита витамина D. B контрольной группе девушек, не имеющих патологию молочных желез, концентрация витамина D была недостаточна, но статистически значимо выше (в пределах 20-30 нг/мл; Ме 20,9 нг/мл) $(p=0,04)$.

ВЫВоды: при заболеваниях молочных желез у девочек подросткового возраста определяется дефицит витамина D. Полученные результаты диктуют необходимость исследование концентрации 25(OH)D и включение препаратов витамина D в комплексную терапию заболеваний молочных желез. 